\title{
Perancangan Sistem Laporan Pengeluaran Dana Bantuan Operasional Sekolah (Bos) Pada Upt Satuan Pendidikan SMP Negeri 6 Tangerang
}

\author{
Achmad Rachmat ${ }^{1}$, Sari Indriana ${ }^{2}$, Amelia Rosa ${ }^{3}$ \\ ${ }^{1,2}$ Program Studi Komputerisasi Akuntansi Universitas Raharja, ${ }^{3}$ Program Studi Sistem \\ Informasi Universitas Raharja \\ Email ; ${ }^{1}$ achmad.rachmat@ raharja.info, ${ }^{* 2}$ sari.indriana@ raharja.info, \\ ${ }^{3}$ amelia.rosa@raharja.info
}

\begin{abstract}
School Operational Assistance (BOS) is a government program that is basically to provide funding for non-personnel operating costs for junior high schools (SMP) as implementing compulsory education programs. In supporting the management of School Operational Assistance (BOS) funds at schools, an information system has been created that can assist in managing BOS funds. The School Operational Assistance Management (BOS) Management Information System was created because inaccurate and incomplete data were often found at the UPT Education Unit of SMP Negeri 6 Tangerang. Causing financial statements every month to be not timely. Therefore this financial statement system was made to support the data to be accurate and complete and the financial statements also become timely. To illustrate the model design and system design using the Unified Modeling Language (UML). The results of this study are a financial reporting system that is designed using the PHP programming language, MySQL database, and laptops are code editors. For testing the system using the Blackbox method, in order to test the functionality of the system.
\end{abstract}

Keywords: Financial Reports, School Operational Assistance (BOS), UPT Education Unit of SMP Negeri 6 Tangerang

\section{Pendahuluan}

Penerapan Teknologi Informasi saat ini telah menyebar hampir di semua bidang tidak terkecuali dalam pengelolaan Dana Operasional Sekolah. Atas dasar Undang-Undang Nomor 20 Tahun 2003 tentang Sistem Pendidikan Nasional mengamanatkan bahwa setiap warga negara yang berusia 7-15 tahun wajib mengikuti pendidikan dasar. Pasal 34 ayat 2 menyebutkan bahwa Pemerintah pusat dan pemerintah daerah menjamin terselenggaranya wajib belajar minimal pada jenjang pendidikan dasar tanpa memungut biaya, sedangkan dalam ayat 3 menyebutkan bahwa wajib belajar merupakan tanggung jawab negara yang diselenggarakan oleh lembaga pendidikan Pemerintah, pemerintah daerah, dan masyarakat. Pada perkembangan dewasa ini memungkinkan seluruh kegiatan pengelolaan dana bantuan operasional memanfaatkan teknologi informasi. Kebutuhan akan Teknologi Informasi sangat berhubungan dengan peran dari pengelolaan dana bos sebagai program standar pendidikan yang diperlukan untuk membiayai kegiatan operasi nonpersonalia selama 1 (satu) tahun sebagai bagian dari keseluruhan dana pendidikan agar satuan pendidikan dapat melakukan kegiatan pendidikan secara teratur dan berkelanjutan sesuai dengan Standar Nasional Pendidikan.

Berdasarkan latar belakang diatas maka diperoleh judul "Perancangan Sistem Pelaporan Pengeluaran Bantuan Operasional Sekolah (BOS) di UPT Satuan Pendidikan SMP Negeri 6 Tangerang". Penelitian ini adalah untuk meningkatkan penggunaan anggaran Bantuan Operasional Sekolah agar tepat pada Komponen Program 8 Standar Pendidikan Nasional yang terdapat didalam Buku Petunjuk Teknis (Juknis) BOS sesuai tahun anggaran yang berlaku. 
Manfaat yang ingin dicapai melalui penelitian ini agar nantinya sistem yang dibangun bisa digunakan untuk mengefisiensikan dan mempermudah pekerjaan dalam pengelolaan dana anggaran bantuan operasional sekolah.

\section{Tinjauan Pustaka}

Mohammad Taufan Asri Zaen, dkk (2018) dalam penelitiannya Sistem Informasi Pengelolaan Dana Bantuan Operasional Sekolah (BOS) SMK Al-Hasanain Beraim Berbasis PHP dan MySQL. Aplikasi ini dapat membantu sekolah dalam proses penyusunan RKAS setiap tahun, membantu sekolah dalam penyusunan realisasi pelaporan penggunaan dana bantuan operasional sekolah setiap triwulannya dalam bentuk BKU dan membantu dengan model pelaporan manual merepotkan pihak sekolah dan dinas, dikemas dalam bentuk sistem berbasis web.

Ishak, dkk 2017 dalam penelitiannya Analisis Penggunaan Aplikasi Pelaporan Dana Bantuan Operasional Sekolah (BOS). Aplikasi ini dibuat dengan melalui proses analisis kebutuhan, proses perancangan aplikasi dan proses pembuatan aplikasi hingga didapatkan hasil yang diinginkan dan Aplikasi ini sangat membantu manajemen SMK Negeri 2 Pontianak dalam Pelaporan Penggunaan Dana Bantuan Sekolah (BOS) sebagai laporan ke Dinas Pendidikan dan Kebudayaan Provinsi Kalimantan Barat.

Penelitian yang dilakukan oleh Ginanjar Setyo Permadi dan Tanhella Zein Vitadiar yang berjudul "Sistem Informasi Laporan Dana Bantuan Operasional Sekolah (BOS) Berbasis Desktop (Studi Kasus Pada SMP Negeri 3 Ponorogo)" Pada SMPN 3 Ponorogo, penyusunan laporan masih dilakukan secara manual menggunakan microsoft excel dan dimana penyusun harus melakukan copy-paste tabel yang akan digunakan dari tabel yang telah disiapkan sebelumnya. Sehingga pembuatan laporan dapat memerlukan waktu lama dan tentu saja dapat mengganggu kewajiban lain sebagai guru. Sistem Informasi dapat didefinisikan sebagai suatu alat untuk menyajikan informasi dengan cara sedemikian rupa sehingga bermanfaat bagi penerimanya[1]. Visual Basic [3]adalah product dari Microsoft, dan merupakan salah satu bahasa pemrograman yang mudah dipelajari serta cukup handal untuk menyajikan sebuah informasi dalam bentuk program desktop. Visual Basic merupakan bahasa pemrograman event drive, dimana program akan menunggu sampai ada respons dari user/pemakai yang berupa kejadian tertentu, misal klik tombol.

\section{Bantuan Operasional Sekolah (BOS)}

Menurut Peraturan Mendiknas nomor 69 tahun 2009, standar biaya operasi nonpersonalia adalah standar biaya yang diperlukan untuk membiayai kegiatan operasi nonpersonalia selama 1 (satu) tahun sebagai bagian dari keseluruhan dana pendidikan agar satuan pendidikan dapat melakukan kegiatan pendidikan secara teratur dan berkelanjutan sesuai Standar Nasional Pendidikan. BOS adalah program pemerintah yang pada dasarnya adalah untuk penyediaan pendanaan biaya operasi nonpersonalia bagi satuan pendidikan dasar sebagai pelaksana program wajib belajar.

Secara umum program BOS bertujuan untuk meringankan beban masyarakat terhadap pembiayaan pendidikan dalam rangka wajib belajar 9 (Sembilan) tahun yang bermutu. Secara khusus program BOS bertujuan untuk :

1. Membebaskan pungutan bagi seluruh siswa SD negeri dan SMP negeri terhadap biaya operasi sekolah, kecuali pada rintisan sekolah bertaraf internasional (RSBI) dan sekolah bertaraf internasional (SBI).

2. Membebaskan pungutan seluruh siswa miskin dari seluruh pungutan dalam bentuk apapun, baik di sekolah negeri maupun swasta.

3. Meringankan beban biaya operasi sekolah bagi siswa di sekolah swasta. 
Sasaran program BOS adalah semua sekolah SD/SDLB, SMP/SMPLB/ SMPT, dan SD-SMP Satu Atap (Satap), baik negeri maupun swasta di seluruh provinsi di Indonesia yang sudah memiliki Nomor Pokok Sekolah Nasional (NPSN) dan sudah terdata dalam sistem Data Pokok Pendidikan (Dapodik).

\section{Analisa dan Perancangan}

\subsection{Sistem Yang Berjalan}

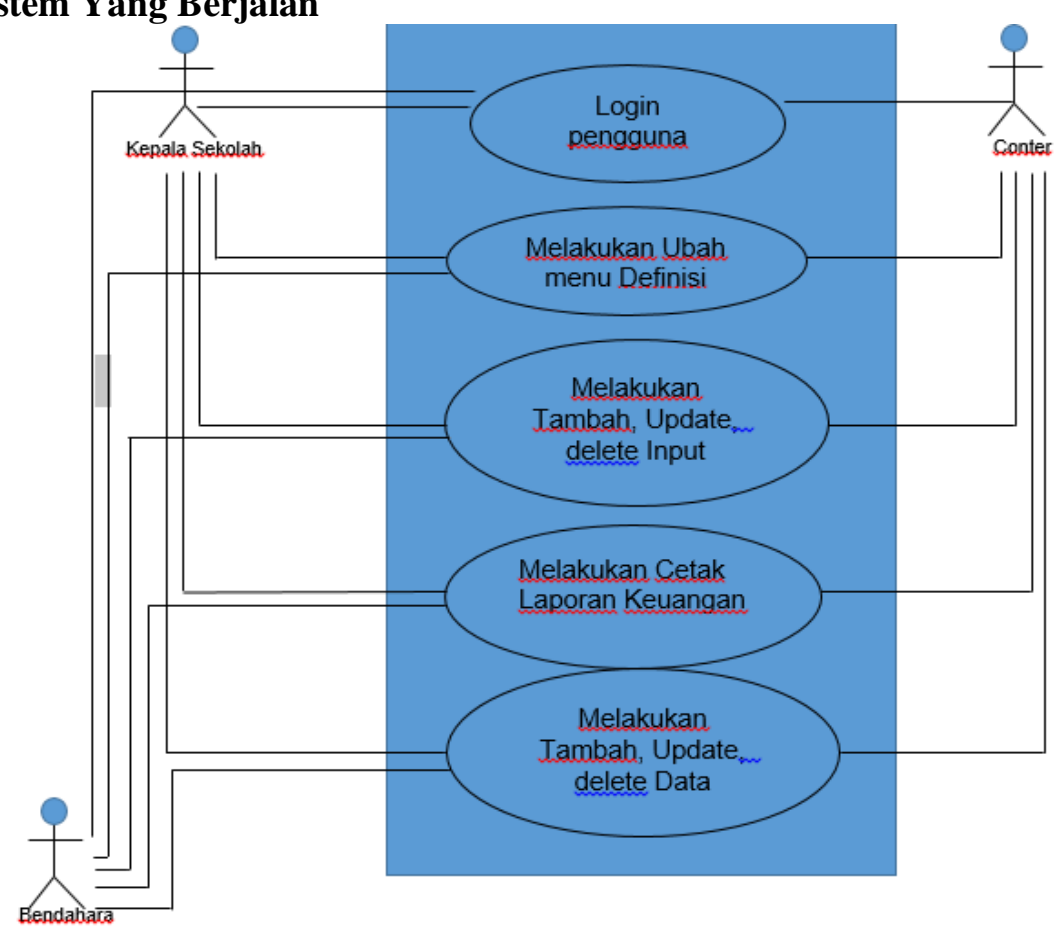

Gambar 1 Sistem yang berjalan

Berdasarkan gambar Usecase Diagram Berjalan diatas terdapat :

a. 1 sistem yang mencakup seluruh pembuatan laporan pada UPT Satuan Pendidikan SMP

Negeri 6 Tangerang

b. 3 actor yang melakukan kegiatan : kepala sekolah, bendahara dan operator.

c. 5 usecase, yang merupakan kegiatan yang dilakukan oleh actor- actor. 


\subsection{Sistem Yang Diusulkan}

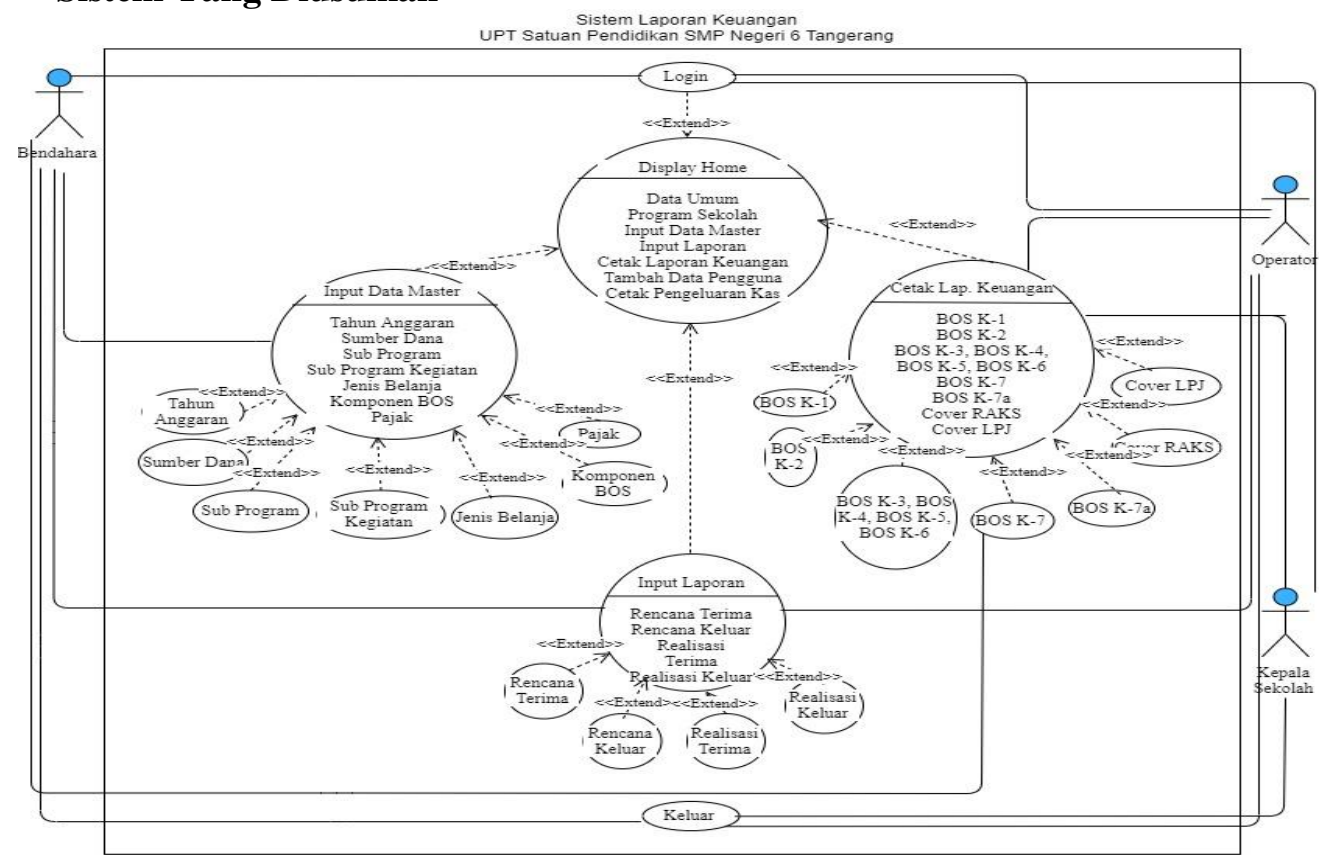

Gambar 2 Sistem yang Diusulkan

Sistem yang diusulkaan memiliki perbedaan dengan sistem lama karena sistem yang dibuat untuk mencapai pengelolaan pelaporan dengan efektif dan efisien. Pada sistem yang diusulkan ini memerlukan beberapa tahapan yang terlihat seperti pada gambar 4.2 Bendahara memberikan data rencana penggunaan dana Bantuan Operasional Sekolah kepada Tata Usaha.

a. Tata Usaha memberikan data rencana penggunaan dana Bantuan Operasional Sekolah dari bendahara yang kemudian diinputkan kedalam sistem dengan menggunakan aplikasi peaporan BOS, data yang diinput tersimpan kedalam pelaporan BOS.

b. Laporan yang telah dibuat kemudian dicetak rangkap tiga dan diperiksa apakah laporan tersebut telah sesuai kebenarannya. Jika laporan belum sesuai maka kepala sekolah memberikan data rencana penggunaan dana BOS ke bendahara. Kemudian bendahara memberikan laporan tersebut kepada tata usaha untuk diinput kembali. Jika laporan telah valid maka laporan tersebut dicetak rangkap tiga, kemudian diserahkan kepada bendahara, kepala sekolah, dan satu sebagai arsip dibagian tata usaha.

4. Implementasi dan Pembahasan

Halaman Login

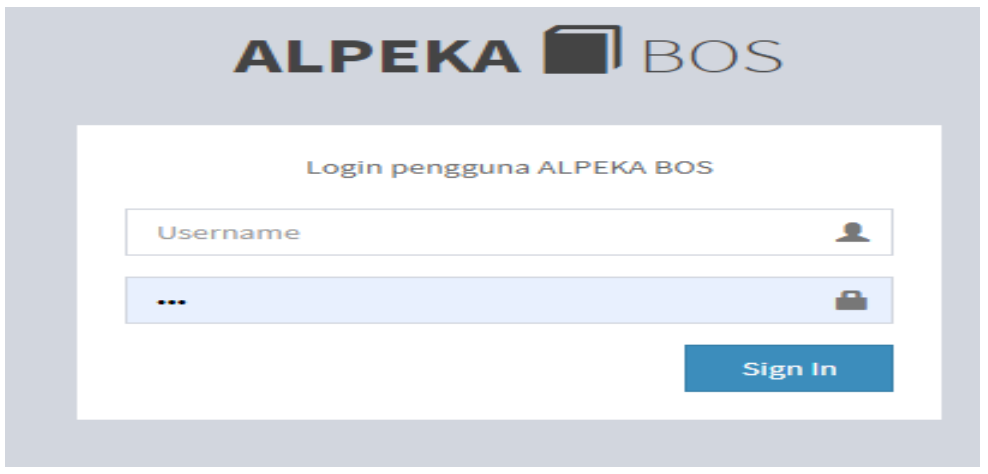

Gambar 3 Tampilan Menu Login 
Pada gambar 5.1 terdapat tampilan halaman login. Kepala Sekolah, Bendahara dan operator, login menggunakan username dan password.Display home
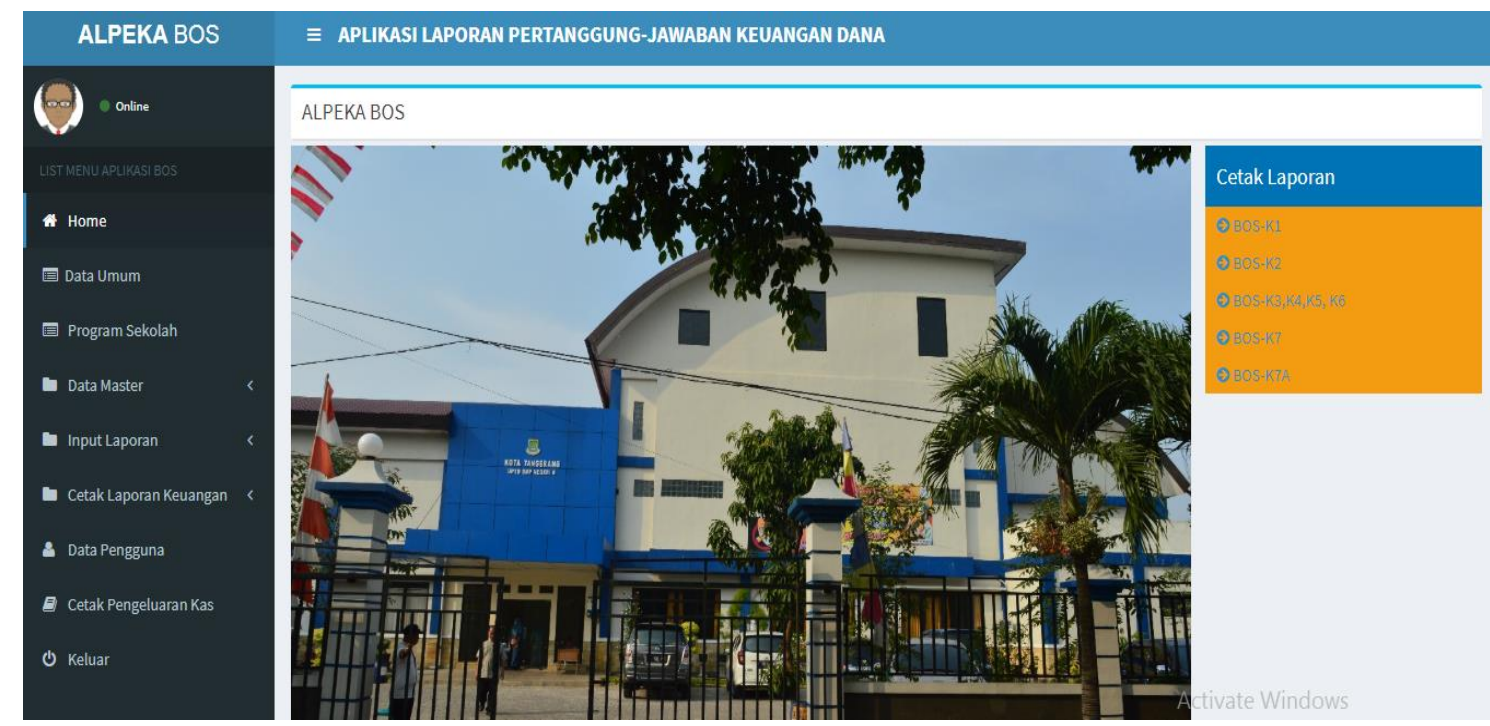

Gambar 4 Display home

Setelah user memasukan username dan password yang benar maka akan muncul halaman utama yang bersikian dasbord, data master, input laporan, cetak laporan keuangan, dana pengguna dan keluar.

Halaman data umum

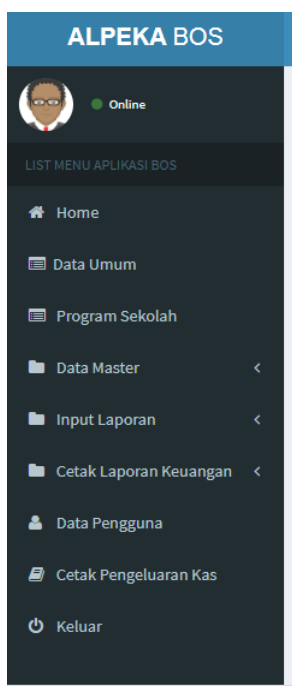

三 APLIKASI LAPORAN PERTANGGUNG-JAWABAN KEUANGAN DANA

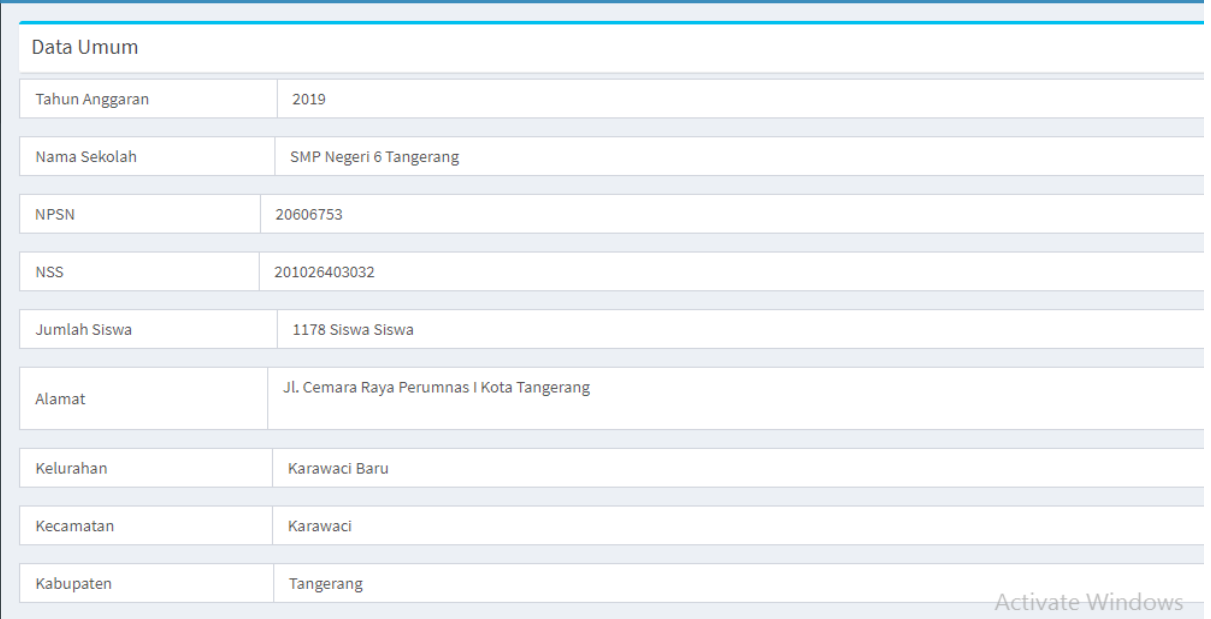

\section{Gambar 5 Halaman data umum}

Pada gambar 5.3 halaman menu data umum, sistem akan menampilkan isian data sekolah dimana data tersebut akan berguna saat membuat laporan. 
Halaman master data

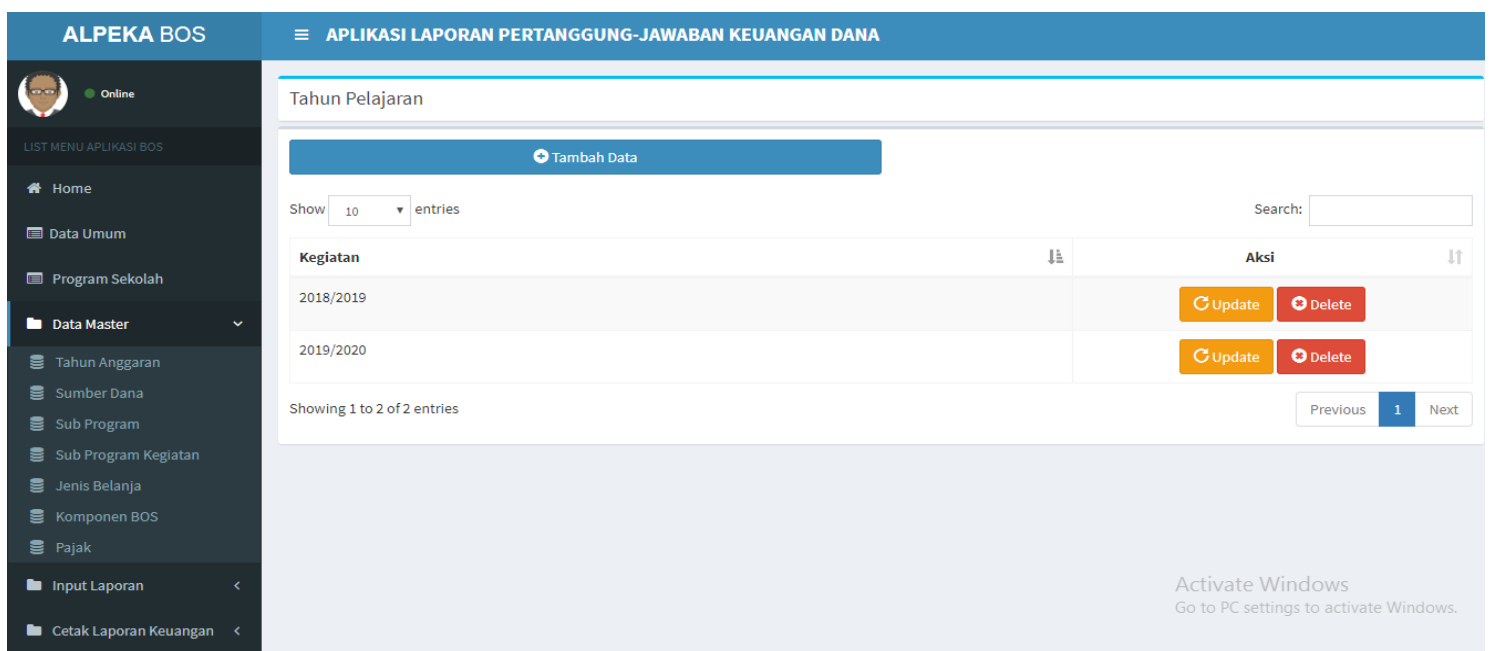

\section{Gambar 6 Halaman master data}

Pada gambar 5.4 halaman master data terdapat beberapa data yang mencakup kegiatan pada UPT Satuan Pendidikan SMP Negeri 6 Tangerang.

Halaman input Laporan

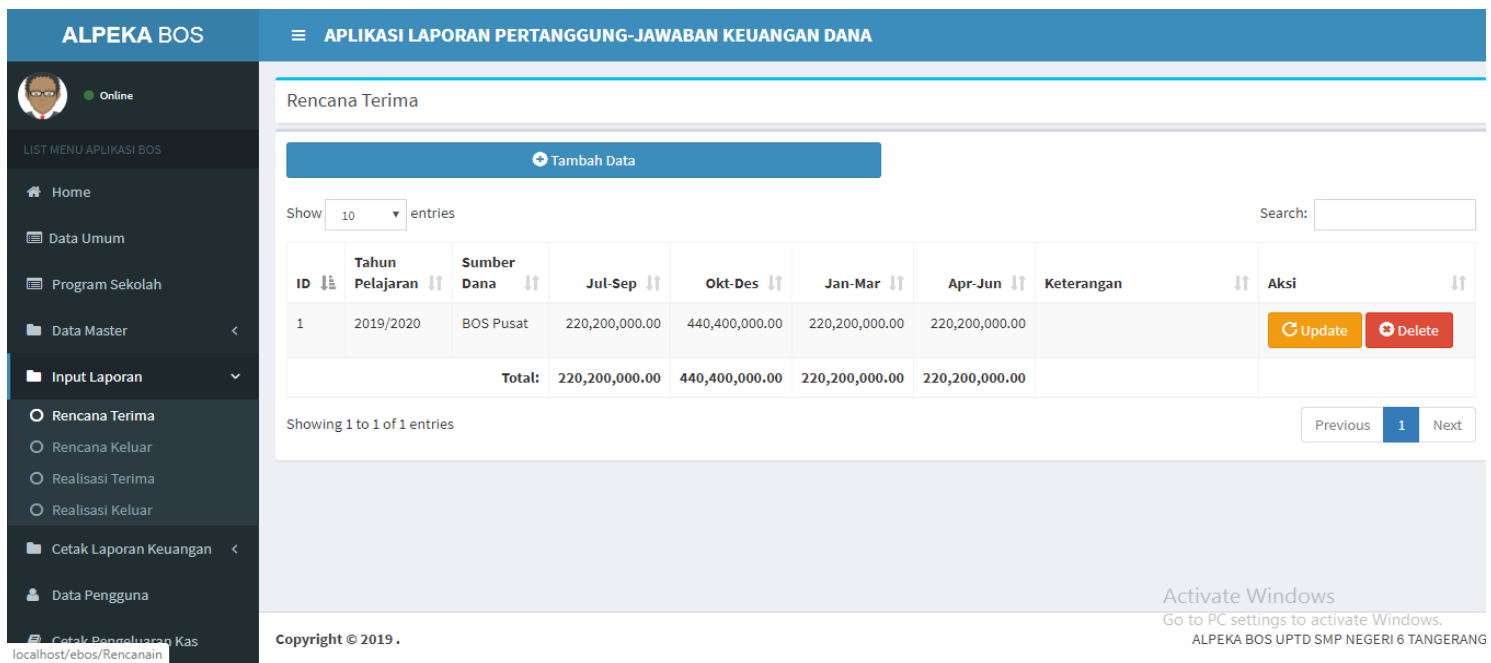

Gambar 7 Halaman input laporan

Pada gambar 5.5 Halaman input laporan dapat diinput oleh bendahara untuk membuat laporan dengan membuat Rencana Kegiatan Anggaran Sekolah (RKAS) pada awal tahun anggaran dengan di rapatkan oleh pihak terkait. 
Halaman cetak laporan keuangan

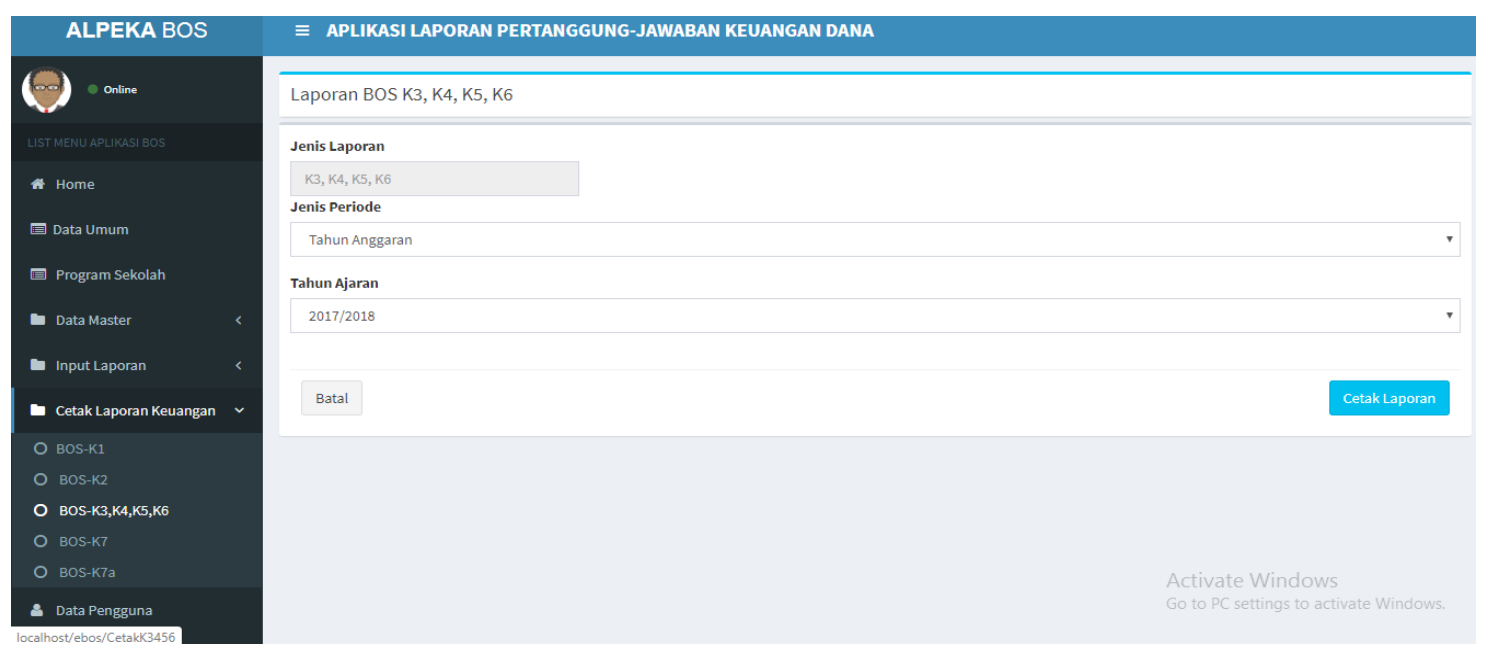

\section{Gambar 8 Halaman cetak laporan keuangan}

Pada gambar 5.6 halaman cetak laporan keuangan, pada halaman ini user dapat memilih laporan apa yang dibutuhkan dan dapat di cetak dalam bentuk pdf dan Mic. Excel.

\section{Kesimpulan}

1. Sistem informasi ini dapat membantu sekolah dalam penyusunan realisasi pelaporan penggunaan dana bantuan operasional sekolah setiap triwulannya dalam bentuk BKU.

2. Aplikasi ini dapat memudahkan admin dalam pengecekan dana bantuan operasional sekolah yang telah dianggarkan.

3. Aplikasi ini sangat membantu dengan model pelaporan manual merepotkan pihak sekolah dan dinas, dikemas dalam bentuk sistem berbasis web.

\section{Saran}

1. Agar dilakukan sosialisasi terhadap program ini kepada intansi yang bersangkutan. Dilakukan peningkatan fitur sesuai dengan kebutuhan yang ada.

2. Pengembangan berikutnya adalah sistem Informasi ini dikelola dalam server online.

\section{Daftar Pustaka}

[1] Petunjuk Teknis, 2019, Bantuan Operasional Sekolah (BOS)

[2] Penelitian yang dilakukan oleh Ishak dalam Jurnal ELKHA Vol. 9, No 2 ,Oktober 2017.

[3] Penelitian yang berjudul "Analisis Penggunaan Aplikasi Pelaporan Dana Bantuan Operasional Sekolah (BOS)"

[4] Penelitian yang dilakukan oleh Mohammad Taufan Asri Zaen dan Baiq Sri Mardiani dalam journal vol. 1 Nomor 2 - 2018. Penelitian ini berjudul "Sistem Informasi Pengelolaan Dana Bantuan Operasional Sekolah (BOS) SMK Al-Hasanain Beraim Berbasis PHP dan My" 
[5] Deti, Leni Kardila dan Herry Mulyono. 2017. "Analisis dan Perancangan Sistem Informasi Penjualan dan Pemesanan Plywood Berbasiskan Web Pada PT. Kumpeh Karya Lestari Jambi”. Jurnal Manajemen Sistem Informasi Vol.2, No.1. Diambil dari : file:///C:/Users/UmiRyn/Downloads/JURNAL-MSI_Analisis-PerancanganSistemInformasi-Penjualan-dan-Pemesanan-Plywood-Berbasiskan-Wrb-Pada-PT.-KumpehKarya-Lestari-Jambi.pdf 